Jaurnal of Environmental Science, Computer Science and

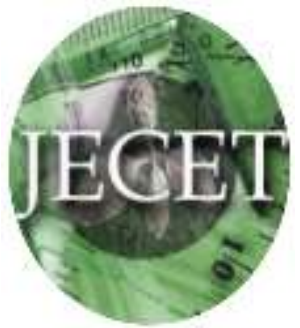
Engineering \& Technology

An International Peer Review E-3 Journal of Sciences and Technology

Available online at www.jecet.org

Section B: Computer Science

Research Article

\title{
The Relationship between Organizational Factors and Technological Factors in ERP Post Implementation Success
}

\author{
Abdulmohsen Alshutairi and Prof. Majed Al-mashari \\ Information systems section, College of computer and information sciences \\ King Saud University, Riyadh, Saudi Arabia
}

Received: 27 March 2020; Revised: 05 April 2020; Accepted: 17 April 2020

\begin{abstract}
The research paper seeks to examine the relationship between organizational factors and technological factors in ERP post implementation success. The paper includes qualitative research that was conducted by means of a literature review, aimed at providing a better understanding of the specific organizational and technological factors in ERP post-implementation success. Findings indicate that technological and organizational factors have a huge influence on ERP post implementation success. Organizational aspects such as company management have to ensure they are fully committed and support the project to ensure its success. In addition, management must also ensure the plans are communicated and understood by the entire company. Lastly, the research also outlined that technologically, proper education and training on the use of the ERP systems has to be provided to all the users of the system, to ensure the effective and efficient use of the ERP system. The users will be able to use the ERP system effectively and therefore contribute to their fulfillment, which ultimately influences the project's implementation success. The limitation is based on the behavioral aspect in post-implementation of ERP, and how success can be promoted, which has not been dealt with. Some suggestions that arise include the fact that entities are required to utilize and accommodate technological as well as organizational factors in the beginning of the project, during the pendency of the project, and in the post-implementation of the ERP project to ensure its success.
\end{abstract}


The outcomes might assist entities planning to set up ERP systems in strategizing their processes and strategies in ensuring its implementation success. The research investigates the relationship between organizational factors and technological factors in ERP post implementation success.

Keywords: post-implementation, organizational, community, technological

\section{INTRODUCTION}

Over the decades, companies around the globe have adopted different (ERP) Enterprise Resource Planning systems because the adoption of ERP is held to be a great determinant in achieving proper competitive advantages. ERP refers to a host of modules and applications which are used to link front and back-office applications, including external and internal supply chains. ERP enables corporations to manage their businesses with various benefits including a reduction in inventories, process flows that are improved, proper data analysis, improved customer services, and increased profits ${ }^{[1]}$. As per the outlined benefits, it is clear to see why the ERP systems are held to be among the most important developments in the business arena, as well as the most commonly accepted typical business software ${ }^{[2]}$.

In some firms, ERP implementations are successful but there are other cases where it was not successful. Especially due to the cost and timeframe. This means that the firms are not able to gain the benefits which are attributed to successful implementation of ERP. According to Zhang et al. ${ }^{[3]}$ research, he indicated that the projects involving ERP implementation were averagely, $178 \%$ above the budget, took two and a half times longer than was anticipated, and delivered only $30 \%$ of the expected benefits. The view is supported by Wang and Chen ${ }^{[4]}$, as per their study, where over $90 \%$ of ERP projects were delayed, and needed further capital injection. In this case, the question that lingers is "why do such ERP implementations fail?' ultimately leading us to inquire, "What are the factors that may influence successful implementation?". As a matter of fact, there have been many attempts to determine and analyze factors which lead to the successful ERP systems implementation. The literature review also indicates that a majority of the studies were set in developed countries such as the United States ${ }^{[5]}$.

United Kingdom, Australia, and Canada. Nonetheless, there are a number of studies which have been held in developing nations including Malaysia, South America, and China ${ }^{[6]}$. Additionally, there are other studies held in the Middle East in a nation such as Bahrain ${ }^{[7]}$. However, the study's focus was not based on the interplay between organizational and technological factors. Therefore, the research aims to analyze and examine the technological and organizational factors which influence the successful implementation of ERP. According to Chien et al. ${ }^{[8]}$, the context in the interplay between the factors might vary from one nation to another. The literature review in this area indicates that there are different factors which may be used in the analysis. This study is based on both technological and organizational factors since they are critical to ERP implementation success ${ }^{[9]}$.

The study findings will be critical in establishing whether the reasons for failures in ERP implementation are universal or generic, irrespective of the nation's economic standing or culture. To be specific, the results or conclusions of the research will enable all companies in the entire globe to plan their actions, specifically those planning future adoption of ERP. In the subsequent sections, the paper deals with the literature review, including highlighting the organizational and technological factors that affect ERP implementation and post-implementation, research methodology, results, discussions and conclusions reached. Lastly, the conclusions and future research implications are highlighted. 


\section{LITERATURE REVIEW}

Successful ERP implementation depends on the point of view that it is evaluated. ERP project managers and consultants point to the success of ERP projects in terms of the project being completed on time and within the set budget. The users of ERP systems judge the success of ERP projects through the seamless operations of the systems. Lastly, the management believes that ERP systems are successful as the company reaches the goals that were set, including other improvements in the business ${ }^{[3]}$. Successful ERPs are measured using two methods. The first measure employs the financial processes, which applies the profits and costs of the company. Second, the entity may apply the self-reported particular ERP success measures ${ }^{[2]}$. Even though it is common to measure success in monetary terms, the measures are generally not allowed because of the difficulty in measuring intangible impacts and benefits ${ }^{[10]}$. Additionally, it is hard to isolate the effect of ERP and other environmental variables that may affect the performance of the organization ${ }^{[8]}$.

Therefore, the research focuses on non-financial and subjective criteria in measuring the success of ERPs. The literature review notes that there are 5 different parts of non-financial and subjective criteria in measuring the success of ERPs. First, previous research on ERP success such as Kamhawi ${ }^{[7]}$, focuses on measures that are related to the success of project management such as time, preset goals and budgets. Secondly, different ERP researchers in the past involved all or various dimensions of the success models by DeLone and McLean in their examination.

Thirdly, different researchers have applied the TAM model set in 1986 by Davis for studies involving the implementation of ERP's. Fourth, different studies involving the successful implementation of ERP's were conducted using the user satisfaction measure ${ }^{[10]}$. Lastly, a majority of previous ERP success researchers used a combination of different measures in their studies ${ }^{[1]}$. From their research, the scholars concluded the success of ERP projects may not be measured via a single measure, or dealing with a single success model. As per this argument, the study investigates the success of ERPs using organizational factors and user satisfaction. In the ERP systems, user satisfaction outlines the extent in which users feel that the accessible ERP software fulfils their wishes ${ }^{[12]}$

ERP systems without any user satisfaction are less likely to be used by the community of users and to lead to positive results in the case of the firm ${ }^{[10]}$. Researchers in the past divided the measure of user satisfaction in in different ways. However, the definition remains consistent. A 13 item tool used for short forms was created by Ives et al. ${ }^{[13]}$ in 1983. The tool used in measuring user satisfaction encompassed three measures of factors including: personnel and departmental service, user knowledge and development, and information product. Researchers such as Sawah et al. ${ }^{[11]}$; and Nah et al. ${ }^{[14]}$, used the method in measuring the satisfaction of users in the case of implementation of ERP systems. Effects on the organization consists of the impact of the implementation of an ERP system on the entity's level of customer service, operational costs, overall gains in productivity, and achievement of specific ERP post implementation goals.

The implementation of such software enables companies with formats of standardized data, proper customer service and retention, as well as improved decision making by management.

Furthermore, the final goal of any ERP system is simply to enhance business performance through the integration of different business processes amongst the different departments and across business boundaries. The integration enables proper flow of information within the entity and between the corporation, its suppliers, and clients. Chien and Tsaur ${ }^{[8]}$ highlighted the organizational influence of ERP systems into intangible and tangible benefits. 
The tangible benefits including reducing workers, inventory, increased productivity, faster financial cycles closing, order management improvement, improved management of cash flow, reduced procurement costs, logistics and transport costs, improved profits and revenues, improvement in delivery times, reduced need for maintenance of systems, internal coordination, and better customer services.

Intangible ERP system benefits include new or improved business processes, improved view of corporate data, improved customer responsiveness, unanticipated cost reduction, global information sharing, added flexibility, improved performance of the business, staff cost efficiency, procurement, inventory, and order/cash management, productivity improvement, and general profitability. Different previous researchers used the impact of the organization in measuring the successful implementation of ERP ${ }^{[15]}$. Even though the organizational impact and user satisfaction are viewed as separate, Jones et al. ${ }^{[16]}$, held that the user satisfaction was part and parcel of organization impact

\section{MATERIALS AND METHODS}

Organizational Factors Influencing Successful ERP Implementation: The main factors that determine the successful ERP post-implementation form important research questions in past research. The implementation of ERP systems involves a long and complex procedure encompassing many factors and conditions that have a huge influence on successful post-implementation. The factors may have a great effect on the outcomes of the ERP implementation project. While the absence of these conditions may lead to unsuccessful ERP implementation. There is variable literature on the factors that are considered important for successful ERP implementation or which are held responsible for its failure. The important factors that influence the successful implementation of ERP projects have been examined from diverse viewpoints. Various researchers have pointed to a number of factors that may be held to be critical to the successful implementation of ERP projects.

For instance, Sommers and Nelson ${ }^{[17]}$ pointed to 22 important factors that determined successful ERP implementation including business dealings education, support from higher management and user software training. Alternatively, Al Mashari et al. ${ }^{[18]}$, noted 12 important ERP aspects such as the selection of the ERP project, education and training, project management, process management, and structural and cultural change management. ${ }^{[19]}$ on the other hand, separated the factors into 10 different categories encompassing top management commitment, proper understanding of the goals, proper project execution and management, a great implementation team, dealing with technical problems successfully, and commitment to change by organization, proper training and education, and performance measures. As per Dezdar and Sulaiman's work ${ }^{[9]}$ in 2009 , these aspects may be categorized into 17 distinct groups that can then be set into 3 major categories. These include the project, system and organizational factors. Dezdar indicated that the organizational factors were critical in determining the post-implementation success of ERPs ${ }^{[20]}$. The organizational factors that were dealt with in this research include support by top management, education and training on ERP, as well as enterprise-wide communication.

Willcocks and Sykes held that sponsorship from senior management, support, participation, and championship are aspects of organizational factors which may influence the success of ERPs. The implementation of ERPs not only involves software systems changes, but involves the transformation and repositioning and rearrangement of different business practices. In this respect, top management officials have to sincerely, publicly and explicitly show their support as an emphasis of the beginning of ERP implementation. 
Lastly, is the education and training aspect? As earlier noted, ERP is a complicated system, meaning proper education and training have to be provided to ensure users apply them efficiently and effectively ${ }^{[15]}$. Training and education will further improve the user's proficiency and knowledge level, therefore improving the individual and subsequent organizational performance. In Nah et al.'s view, proper training may increase the probable success of implementation of ERP systems, while the lack of such training will be a hindrance to implementation. Proper education and training might also enable the organization in building positive sentiments in regards to the system. Additionally, training might assist ERP users in adapting and adjusting to the changes taking place in the organization through the implementation of the system. Lastly, training improves utility, and reduces the resistance by users, which ultimately improves the likelihood of success and use of ERP systems [15]. Implementation of ERP systems without proper training might have many drastic costs ${ }^{[17]}$.

Technological factors Influencing Successful ERP Implementation: Technological factors analyze both external and internal technological means which are accessible to the entities. The three factors include internal expertise of ERP, project management, and ERP configuration.

ERP Internal Expertise: ERP internal expertise is referred to as the internal capacity of operators and managers in dealing with problems from the system through the adaptation, refinement, and ensuring proper maintenance. In general, managers do not have the right view of the needs of the ERP, its competences, and how to troubleshoot the system ${ }^{[21]}$. It is therefore important to have experts who understand the systems and its problems. Most of the ERP sellers do not accept any responsibility for internal network or hardware problems, so the internal experts of ERP have the required knowledge to offer quality support services. Additionally, through the adoption of the ERP and its running in the entire entity, the IT department will actually be in charge of troubleshooting and debugging the ERP system, constantly modifying and refining it as per the users and business needs.

ERP Configuration: ERP configuration denotes proper configuration and structuring of ERP systems and programs within an organization ${ }^{[15]}$. It is important to have proper configurations of ERP to ensure an effective and optimized ERP package is offered. On the other hand, ERP structures that are unclear will lead to increased likelihood for crises as a result of the non-effective and weak ERP functions. Because of the ERP weaknesses, there are many problems and issues associated with ERP implementation ${ }^{[22]}$. These will cause ERP collapses in the course of daily functioning. A properly configured ERP system makes accurate problem detection simpler in the course of routine operations. Proper ERP configuration and structuring improves the chances of the entity achieving managerial and operational benefits.

Project Management: The most decisive technological element in the failure or success of ERP implementation is the abilities, skills, experience, and knowledge of the project manager. The project manager is in charge of monitoring, coordination and scheduling the organization's activities to make sure that the project objectives are successfully realized ${ }^{[23]}$. Project managers in charge of ERP systems need to understand both the technological and organizational aspects, and strike a balance between the two. Lastly, ERP project managers need to understand the effect of the implementation of ERP on the organization, and work alongside other managers to make sure there is seamless transition from the previous processes to the new system.

Research Methodology: The purpose of this research is to examine the organizational factors that affect ERP systems successful implementation. The paper includes qualitative research that was conducted, aimed at providing a better understanding of the specific organizational and technological factors in ERP post-implementation success. Qualitative research is not based on manipulation of variables or imposition of the operational variables definition on the selected studies ${ }^{[24]}$. It was 
employed with the aim of gaining better understanding via first-hand experiences and reporting the truth. The research also includes peer-reviewed articles that institutes the validity of the research on the basis of knowledge by researchers and experts in the field, which prevents the acceptance of fabricated work.

\section{RESULT AND DISCUSSION}

Discussions, Analysis and Findings: From the research, it is evident that user satisfaction has a huge influence on organization. This infers that the higher the satisfaction level, the more likely the success of ERP implementation. The inferences are consistent with results from Reinhard and Bergamaschi's research ${ }^{[25]}$. Research also indicate that there is a connection between support from top management and its impact on any organization. In this case, it can be concluded that as an organizational factor, support from top management is important for the success of ERP implementation, irrespective of the economic standing, and culture of the nation.

In addition, effective communication is also an important organizational factor that determines the successful post-implementation of ERP's since employees are aware of the status of the company. Customers and suppliers should be kept informed frequently to understand what is the status of the entities activities that border on ERP implementation. A proper and coordinated plan for communication is effective in enabling the entity to reach or achieve its goals, benefits, timelines, and common ideas, where regular executive level results are held to be important. The communication plan needs to cover different areas inclusive of the ERP implementation rationale, changes to business process management, changes in the required software modules, change management tactics and strategies briefings, and setting different points of contact.

The technological aspects that affect ERP post-implementation success include the internal expertise of ERP, project management, and ERP configuration. ERP internal expertise is referred to as the internal capacity of operators and managers in dealing with problems from the system through the adaptation, refinement, and ensuring proper maintenance. Project management is important since the project manager is in charge of monitoring, coordination and scheduling the organization's activities to make sure that the project objectives are successfully realized. ERP configuration denotes proper configuration and structuring of ERP systems and programs within an organization. The three factors work hand in hand to ensure the success of ERP post-implementation

Relationship between Organizational and Technological Factors in Ensuring Successful ERP Implementation: It is evident that technological and organizational factors are crucial to successful ERP implementation. The interplay between the importance of the factors changes throughout the life-cycle of the project ${ }^{[26]}$. In the beginning, organizational factors are important, while the technological factors gain relevance in the middle of the ERP implementation. This indicates that organizational factors are relevant throughout the entire implementation but technological factors become even more critical in the implementation and post-implementation phases.

In the project preparation phase, organizational factors are important compared to the technological factors. A proper project management function, continuous support for management and schedules set with timelines are critical strategic aspects, while great interfaces and ample infrastructure are critical technological aspects ${ }^{[26]}$. The factors are relevant in this phase since it is mostly dedicated to project organization and planning. Therefore, the importance of the organizational aspects cannot be understated. In the course of the project, however, the forms of organizational factors change. For instance, the project manager function is deemed to be the most important throughout the phases, 
although the relevance of continuous support from management decreases. Change, the participation and involvement of users, and using the right consultants also stand out as important organizational factors.

The next phase is dedicated to the modelling and analysis of the business. In this step, the relevance of organizational factors reduces, with the rise in relevance of technological factors. A well-defined project manager function, participation and involvement of users as well as using the right consultants are the required organizational aspects, while a defined interface, and proper infrastructure in addition to a formalized testing plan are critical technological factors in this case ${ }^{[26]}$. Most of the technological factors are important in this phase and may determine the success or failure of the venture or project.

In the last phase, the relevance of organizational factors increases with a decrease in the relevance of technological factors. A good project manager, user participation and involvement are still the most important organizational factors. For this phase, good flow of communication in and out of the organization gains relevance. The good interfaces and proper infrastructure are still the highest ranked technological aspects. The segment is dedicated to training users and systems testing. It is in this phase that final system adjustments are conducted.

In the Post ERP implementation phase, organizational factors gain relevance compared to the technological factors. A worthy project manager function and good communication flow inside and outside the organization still stand out as critical organizational factors. Technological factors' relevance, on the other hand, gain normal relevance, becoming slightly significant ${ }^{[26]}$. The phase is then dedicated to the maintenance of the system. It is recommended to involve and communicate with subordinates and involve them in the entire process to ensure project success in the long-run. The results in the analysis have huge implications on the manner in which organizations are required to manage the implementation of ERP projects. Some suggestions that arise include the fact that entities are required to utilize and accommodate organizational factors in the beginning of the project, during the pendency of the project, and in the post-implementation of the ERP project to ensure its success. Lastly, the shift from organizational to technological factors has to be managed carefully.

Limitations and Future Research: In the research, the conceptual framework was not examined empirically. While some crucial factors in the successful post-implementation of ERP introduced different aspects such as data accuracy, implementation teams, communication, as well as the ERP communication strategy, a comprehensive analysis of the success of the project in the postimplementation phase was not presented before, therefore, studies have to be set to examine the empirical relationship. The second limitation is based on the behavioral aspect in post-implementation of ERP, and how success can be promoted, which has not been dealt with. Studies in the future may be based on how different behavior including groups or individual influence, particularly in the ERP aspect, may impact success at various stages and levels. Additionally, while some of the researchers focus on the influence of the critical factors to ERP successful implementation, as well as in the post implementation phase, there is need to examine the impact of the crucial factors on other factors.

According to Sternad et al. ${ }^{[27]}$, his study analyzed the influence of external factors on usage of ERP and examine the effect of training and communication on general ERP benefits . Shao et al. ${ }^{[28]}$, analyzed the general impact of knowledge sharing and organizational culture on leadership and successful ERP implementation. Due to the lack of adequate research on the critical factors that affect ERP, namely communication, data accuracy, ERP implementation strategy, and their effect on successful ERP post implementation, the research proposes that studies in the future should not simply focus on the examination of the impact of the critical factors on the empirical post- 
implementation success of ERP, and should go further in exploring the origin of these factors, and the impact they may have on other crucial aspects.

\section{CONCLUSIONS}

As per the literature review that pertains to successful ERP implementation, it was held that there is a gap in the research since most of the literature focus on factors which influence successful ERP implementation. The relationship between technological and organizational factors have a huge impact on successful ERP post-implementation. Findings indicate that technological and organizational factors have a huge influence on ERP post implementation success. Organizational aspects such as company management have to ensure they are fully committed and support the project to ensure its success. In addition, management must also ensure the plans are communicated and understood by the entire company. Organizational factors such as a well-defined project manager function, participation and involvement of users, using the right consultants, enterprise wide communication, support from top management, are deemed crucial in ensuring ERP postimplementation success. The research points out that there is a positive correlation between support from top management, ERP education and training, and enterprise-wide communication in the success of ERP implementation. The users will be able to use the ERP system effectively and therefore contribute to their fulfillment, which ultimately influences the project's implementation success. In this case, it is clear to see that the interplay between technological and organizational factors is important in ensuring successful implementation of ERP. The importance of technological and organizational factors shifts in the course of the project. Organizational factors gain a lot of relevance in the beginning and end of the project while the technological factors are critical in the middle of implementing ERP. However, the organizational aspects are important throughout the entire ERP implementation. Based on the literature review that pertains to implementation of ERP, it is evident that there is a huge gap in the literature as pertains to the implementation of ERP. Most of the studies of aspects that have an influence on successful ERP implementation focus on developed nations. On the other hand, there are less studies that were conducted on ERP post-implementation. Some suggestions that arise include the fact that entities are required to utilize and accommodate organizational factors in the beginning of the project, during the pendency of the project, and in the post-implementation of the ERP project to ensure its success. Lastly, the interplay between organizational and technological factors has to be managed carefully.

\section{REFERENCES}

1. J.C.Fan and K. Fang, ERP Implementation and information systems success: a test of DeLone and McLean's model, PICMET (Portland International Center for Management of Engineering and Technology) 2006 Proceedings, 9-13 July, Istanbul, pp. 1272-8.

2. J.R.Muscatello and I.J.Chen, Enterprise Resource Planning (ERP) implementations: theory and practice, International Journal of Enterprise Information Systems, 2008, 4, 1, 63-78.

3. Z.Zhang, M.K.O. Lee, P. Huang, L. Zhang and X. Huang, A framework of ERP systems implementation success in China: an empirical study, International Journal of Production Economics, 2005, 98, 56-80.

4. E.T.G.Wang and J.H.F.Chen, The influence of governance equilibrium on ERP project success, Decision Support Systems, 2006, 41, 708-27. 
5. J.Bradley, Management based critical success factors in the implementation of enterprise resource planning systems, International Journal of Accounting Information Systems,2008,9 , 3 175-200

6. F.H.Nah, Z. Islam and M.Tan, Empirical assessment of factors influencing success of enterprise resource planning implementations, Journal of Database Management,2007, 18 , 4, 26-50.

7. E.M.Kamhawi, Critical factors for implementation success of ERP systems: an empirical investigation from Bahrain, International Journal of Enterprise Information Systems, 2007, 3 , 2, 34-49.

8. S.W.Chien and S.M.Tsaur, Investigating the success of ERP systems: case studies in three Taiwanese high-tech industries", Computers in Industry, 2007, 58, 783-93.

9. S. Dezdar and A. Sulaiman, Successful enterprise resource planning implementation: taxonomy of critical factors", Industrial Management \& Data Systems, 2009,109, 8, 1037-52.

10. J.H.Wu and Y.M.Wang, Measuring ERP success: the key-users' viewpoint of the ERP to produce a viable IS in the organization, Computers in Human Behavior, 2007, 23, 1582-96.

11. S.E.Sawah, A.A.F. Tharwat and M.H.Rasmy, A quantitative model to predict the Egyptian ERP implementation success index", Business Process Management Journal, 2008, 14, 3,288306.

12. T.M.Somers,K. Nelson and J.Karimi,Confirmatory factor analysis of the end-user computing satisfaction instrument: replication within an ERP domain, Decision Sciences,2003, 34 ,3,595621

13. B.Ives, M.H. Olson, and J.J.Baroudi, The measurement of user information satisfaction, Communication of the ACM, 1983,26,10, 785-93.

14. F.H.Nah and S.Delgado, Critical success factors for enterprise resource planning implementation and upgrade, Journal of Computer Information Systems, 2006, 46, 5, 99-113.

15. J.Bradley, Management based critical success factors in the implementation of enterprise resource planning systems, International Journal of Accounting Information Systems, 2008, 9 , 3, 175-200.

16. M.C.Jones, R.W. Zmud, and T.D.Clark, ERP in practice: a snapshot of post-installation perception and behaviors, Communications of the Association for Information System, 2008, 23, 437-62.

17. T.M.Somers and K.G.Nelson, A taxonomy of players and activities across the ERP project life cycle, Information \& Management, 2004,41, 257-78.

18. M. Al-Mashari, S.K. Ghani and W.Al-Rashid, A study of the critical success factors of ERP implementation in developing countries, International Journal of Internet and Enterprise Management, 2006, 4 , 1, 68-95.

19. E.J.Umble, R.R. Haft and M.M.Umble,Enterprise resource planning: implementation procedures and critical success factors , European Journal of Operational Research,2003,146, 241-57. 
20. Y. Zhu, Y. Li, W. Wang and J.Chen, What leads topost-implementation success of ERP? An empirical study ofthe Chinese retail industry. International Journal ofInformation Management, 2010, 30(3), 265-276.

21. A.M.Asmamaw,Analysis of the Critical Success Factors for ERP Systems Implementation in U.S. Federal Offices)2012, http://link.springer.com/chapter/10.1007/978-3-642-37021-2_15

22. E. Uppström, C.M. Lönn, M. Hoffsten \& J. Thorström, New implications for customization of ERP systems. In 2015 48th Hawaii International Conference on System Sciences 2015, 42204229, IEEE.

23. A.Badewi \& E.Shehab, The impact of organizational project benefits management governance on ERP project success: Neo-institutional theory perspective. International Journal of Project Management, 2016, 34(3), 412-428.

24. U. Flick, Designing qualitative research. Sage.2018.

25. N.Reinhard and S. Bergamaschi, Management of ERP systems implementation in Brazil, Proceedings of the Seventh Americas Conference on Information Systems (AMCIS), Boston, MA,2001, 1098-104.

26. J.Esteves \& J.A.Pastor, Organizational and technological critical success factors behavior along the ERP implementation phases. In Enterprise information systems VI, 2006, 63-71, Springer, Dordrecht.

27. S.Sternad, M. Gradisar and S.Bobek, The influence of external factors on routine ERP usage. Industrial Management\& Data Systems, 2011, 111(9), pp. 1511-1530.

28. Z.Shao, Y. Feng and L. Liu, The mediating effect of organizational culture and knowledge sharing on transformational leadership and Enterprise Resource Planning systems success: An empirical study in China. Computers in Human Behavior.2012, 28(6), pp. 2400-2413.

\section{Prof. Majed AL-Mashari ,}

Information systems section, College of computer and information sciences

King Saud University, Riyadh, Saudi Arabia

malmashari@yahoo.com

Date of publication on line 17.04.2020 